\title{
Recent Advances in the Inhibition of the IL-4 Cytokine Pathway for the Treatment of Allergen-Induced Asthma
}

\author{
Oliver Massey ${ }^{1,2}$ and Cenk Suphioglu $1,2, *$ (i) \\ 1 NeuroAllergy Research Laboratory, School of Life and Environmental Sciences, Deakin University, Geelong, \\ VIC 3216, Australia; omassey@deakin.edu.au \\ 2 Institute for Mental and Physical Health and Clinical Translation (IMPACT), Deakin University, Geelong, \\ VIC 3216, Australia \\ * Correspondence: cenk.suphioglu@deakin.edu.au
}

check for updates

Citation: Massey, O.; Suphioglu, C. Recent Advances in the Inhibition of the IL-4 Cytokine Pathway for the Treatment of Allergen-Induced Asthma. Int. J. Mol. Sci. 2021, 22, 13655. https://doi.org/ $10.3390 /$ ijms 222413655

Academic Editor: Anagha Malur

Received: 19 November 2021 Accepted: 15 December 2021 Published: 20 December 2021

Publisher's Note: MDPI stays neutral with regard to jurisdictional claims in published maps and institutional affiliations.

Copyright: (c) 2021 by the authors. Licensee MDPI, Basel, Switzerland. This article is an open access article distributed under the terms and conditions of the Creative Commons Attribution (CC BY) license (https:// creativecommons.org/licenses/by/ $4.0 /)$.

\begin{abstract}
The IL-4 and IL-13 cytokine pathways play integral roles in stimulating IgE inflammation, with the IL-4 cytokine being a major cytokine in the etiology of thunderstorm asthma, atopic dermatitis, and allergic rhinitis. The increasing prevalence of thunderstorm asthma in the younger population and the lessening efficacy of corticosteroids and other anti-inflammatories has created a need for more effective pharmaceuticals. This review summarizes the IL-4 and IL-13 pathways while highlighting and discussing the current pathway inhibitors aimed at treating thunderstorm asthma and atopic dermatitis, as well as the potential efficacy of peptide therapeutics in this field.
\end{abstract}

Keywords: interleukin 4 (IL-4); interleukin 13 (IL-13); immunoglobulin E (IgE); STAT6; immunotherapy; peptide therapeutics

\section{Introduction}

Allergies are a worldwide issue, with approximately $20 \%$ of the global population suffering from allergy-caused symptoms including rashes (atopic dermatitis), runny nose (allergic rhinitis), and life-threatening breathing problems (allergy-induced asthma) [1]. This creates a gargantuan burden on global healthcare systems and lowers the quality of life for patients [1]. The term "allergy" was first described by Clemens von Piquet in 1903, wherein he determined that symptoms of disease were not solely caused by external infection, but also by the body's response to said infection [2]. Since its conception, the term "allergy" has grown to describe a wide field within clinical immunology with even wider symptoms. One of the more serious symptoms of allergies is allergic asthma. Asthma currently affects as many as 339 million people globally, and is ranked 16th among the leading causes of years lived with disability and 28th among the leading causes of burden of disease [3]. The prevalence of asthma and allergies has greatly increased in recent decades, which can be attributed to a variety of factors, such as rapid urbanization and industrialization causing the release of air pollutants, smoking, exposure to mold, diet, and obesity, as well as genetic susceptibilities [3,4]. Additionally, it is still unknown whether the COVID-19 pandemic has had an effect on the prevalence of asthma; however, current reports from the United States suggest an increased risk of asthma in young people diagnosed with COVID-19 [5-7].

Asthma is commonly defined as smooth muscle contractions and chronic inflammation of the trachea and other associated airways, and can be caused by a variety of pathways involving gene and environmental interactions [8]. Research has revealed that over 100 genes are involved with pathways leading to asthma, but no single gene has been identified as the sole culprit, making treating asthma at its cause an arduous process [9]. Due to this, treatments for asthma have been heavily focused on the relief of symptoms on a day-to-day schedule, rather than addressing the underlying causes. These treatments are typically inhaled corticosteroids for short-term relief, or longer-lasting therapeutics 
such as long-acting $\beta 2$-adrenergic receptors, leukotriene receptor antagonists, long-acting muscarinic antagonists, and for the most severe of symptoms, IgE-specific monoclonal antibody immunotherapy, also called omalizumab [10]. These treatments are all directed towards the relief of symptoms, rather than addressing the underlying pathways dysregulated in asthma. Of the standard therapeutic treatments, some are more successful in certain individuals than others. Certain trials have concluded that for $20 \%$ of their patients, asthma remained uncontrolled when treated with traditional corticosteroids [11].

The interleukin 4 and 13 pathways play integral roles in both type 1 allergy hypersensitivity and type 2 immunity [12,13]. Moderated by T-helper- 2 lymphocytes, the IL-4 pathway causes the release of interleukin-4 from the aforementioned lymphocytes, which affects nearly every cell, while creating a variety of effects [14]. The IL-4 receptor is expressed on nearly every cell; however, due to the unique STAT6 molecule, the cellular response can differ between cells. For epithelial cells within the airways, cytokines IL-4 and IL-13 can cause muscle contraction and chronic inflammation, leading to asthmatic symptoms. Due to the integral role that the IL-4 pathway plays in allergen-induced asthma, it is a prime candidate for inhibitory drugs to treat allergic asthma.

\section{IL-4 and IL-13 Pathways}

Interleukins 4 and 13 are key cytokines in allergic inflammation, and are secreted by numerous immune cells, most commonly T-helper-2 lymphocytes [15]. The release of these cytokines causes the production of immunoglobulin E [ $\operatorname{IgE}]$ by B lymphocytes, as well as causing a range of effects in other cells. The introduction of IgE to mast cells causes an immediate allergic inflammation and response. IL-4 plays another role in asthma through the induction of mucin gene expression, causing the hypersecretion of mucus from goblet cells within the airways. The IL- 4 cytokine induces all these processes and more when released, causing the symptoms observed within allergic asthmatics.

When T-lymphocytes release IL-4, all cells carrying the receptor respond. While nearly all cells carry this receptor, overall cell responses differ between cell types due to the unique STAT6 transcription factor involved with this signaling pathway, which activates different intracellular transcription pathways dependent on that cell type. This allows for IL-4 to elicit a range of responses from a wide variety of cell types, making it the ideal candidate for therapeutic intervention. IL-13 differs from IL-4, as it is an effector cytokine that regulates smooth muscle contraction and mucus production. Similar to the IL-4 signaling system, IL-13 works extracellularly through cell membrane receptors.

The IL-4 signaling pathway involves numerous transmembrane peptides and intracellular signaling molecules, which produce unique responses dependent on cell type. The transmembrane receptor for IL-4 is IL- $4 \mathrm{R} \alpha$. IL- $4 \mathrm{R} \alpha$ is expressed in most cells, although in low numbers. The role of this transmembrane peptide chain is to form a complex with IL-4, at which point it will recruit a secondary receptor chain. There are two secondary receptor chains, IL-2Ryc and IL-13Ra1, which are expressed within different cell types. Nonhematopoietic cells express IL-13Ra1, whereas IL-2Ryc is expressed in low levels or absent. The opposite of this is true for lymphocytes, which express IL-2Ryc, but little to no IL-13Ra1. The receptor complex formed between IL-4R $\alpha$ and IL-2yc is herein referred to as the type 1 IL-4 complex, whereas the complex formed by IL- $4 \mathrm{R} \alpha$ and IL-13R $\alpha 1$ is herein referred to as the type 22 IL-4 receptor complex. Once the three signaling molecules have been recruited, the receptor has formed a functional complex, which then undergoes a conformational change, allowing for the activation of intracellular signaling machinery [16,17].

Once the receptor complex is formed and has undergone the conformational change to be functional, associated intracellular signaling molecules will undergo auto- and crossphosphorylation, resulting in their activation. The intracellular machinery activated is largely dependent on the third signaling chain recruited to the transmembrane complex, although they all belong to a signaling family called the Jak kinases. The activation of these Jak kinases causes the phosphorylation of other kinases and critical $Y$ residues within the intracellular domains of IL-4R $\alpha$. Once phosphorylation has occurred, these $Y$ residues 
function as "docking sites" for intracellular signaling molecules, most commonly STAT6. STAT6 is an intracellular signaling molecule that grants the IL-4 pathway the unique property of producing different cellular responses dependent on cell type. Upon contact with the activated IL-4 signaling complex, STAT6 molecules homodimerize and translocate to the nucleus, binding to specific DNA sequences to influence the cells' overall expression. The IL-4 signaling pathway is not only involved with transcriptional change, but is also involved with the downregulation of elicited signals. Pathways that downregulate signaling pathways are increased by IL-4 activation, limiting the duration of the IL-4 and associated signals.

The IL-13 pathway shares many functional similarities with the IL-4 pathway. IL-13 has two receptors similar to the IL-4 pathway, but differs by utilizing two separate binding chains. The type of receptor that is formed is dependent on which chain the IL-13 molecule binds to, unlike IL-4, which is determined after binding. The IL-13 pathway also affects the IL-4 pathway, as studies have displayed the complex formed by IL-13 and its type 1 alpha receptor (IL-13R $\alpha 1$ ) lessen the intracellular effect of the type 2 IL-4 receptor complex, therefore reducing the cellular response. The IL-13 pathway concludes in the activation of STAT6 molecules and insulin receptor substrates (IRSs), which produce cellular responses at a transcription level. Unlike the IL-4 pathway, the IL-13 pathway is a poor activator for IRS molecules. Whilst STAT6 activates allergy symptoms, IRSs are involved with cellular proliferation. Both the IL-4 and IL-13 pathways play roles in the inflammation associated with allergies; however, they also play fundamental roles in cellular function [18-20] (Figure 1).

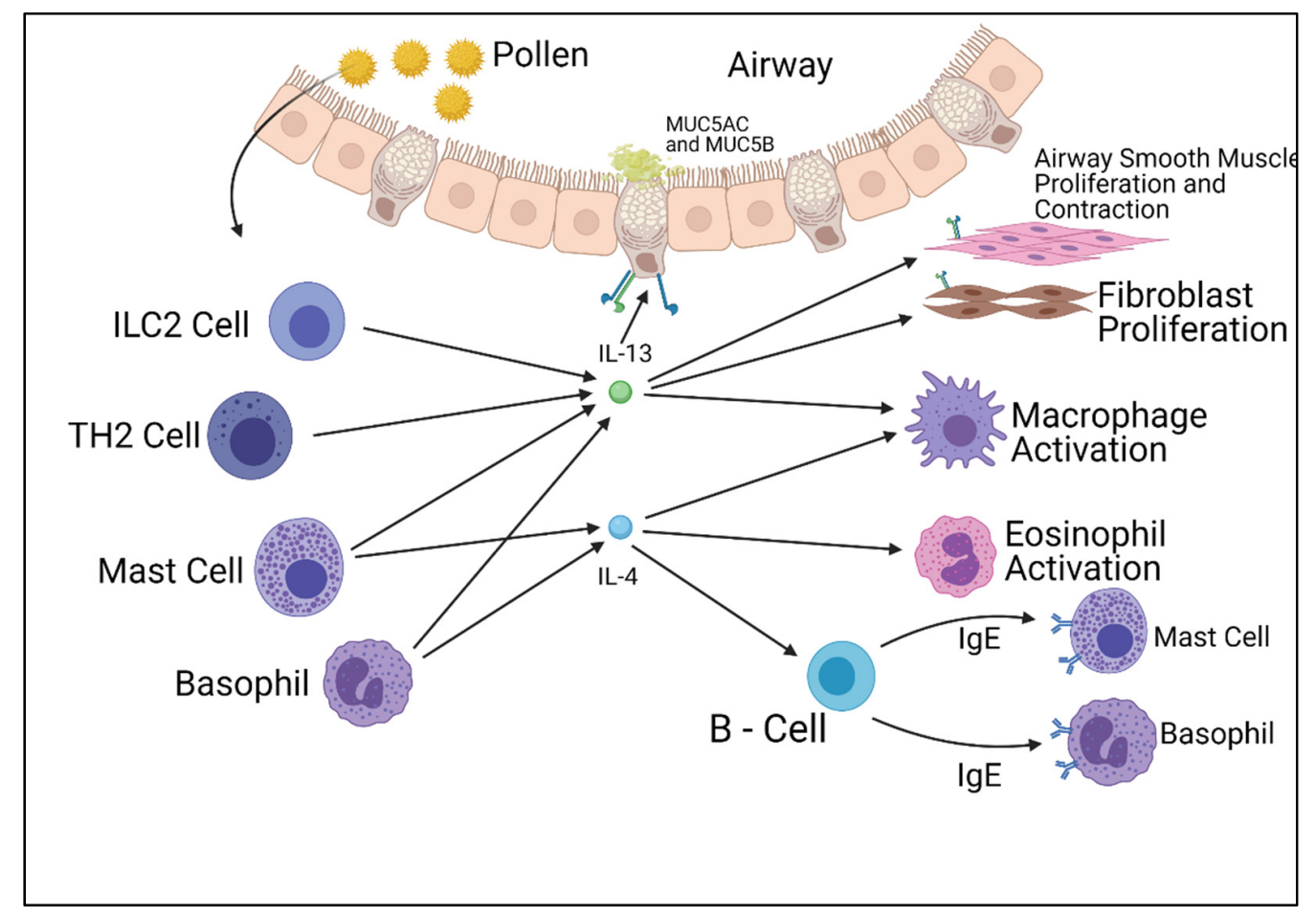

Figure 1. Summary of the cells responsible for the production of IL-4 and IL-13 and their effects on other cell types. Figure was created by the authors and reproduced with permission from BioRender.com (accessed on 19 November 2021).

STAT6 is activated by both the IL-4 and IL-13 pathways, though this is largely dependent on the cell type, as are the effects of the STAT6 molecule. IL-4, however, can induce further intracellular signaling pathways, including Sos/Ras, PI3K/Akt, PKB/mTOR, and PKC. These alternative pathways, coupled with the transcriptional influence of STAT6, create variable cellular responses to the introduction of the IL-4 or IL-13 cytokines. While 
having effects on many different cell types, the main functions of the IL-4 and IL-13 pathways are the production of human immunoglobulin $\mathrm{E}$ and T-helper cell differentiation, which then brings on the clinical symptoms of atopic dermatitis, allergic rhinitis, and allergic asthma.

STAT6 is a complex transcription factor responsible for exerting the effects of IL-4 and IL-13. Following phosphorylation by IL-4 and IL-13 receptor kinases, the phosphorylated STAT6 protein migrates to the nucleus to act as a transcription activator. It has been proven through mice knockout studies that STAT6 is required for allergy development; however, the genetic profile activated varies greatly between cell types. When STAT6 is activated within B-lymphocyte cells, STAT6 upregulates the Ig $\varepsilon$ heavy chain and CD23 gene, which encodes for the IgE heavy chain and IgE receptors [21-23]. However, in Th2 cells, STAT6 upregulates gata3, another transcription factor responsible for many biological functions, and CRTH2, a gene involved in eosinophilic and allergic inflammation [24] (Figure 2).

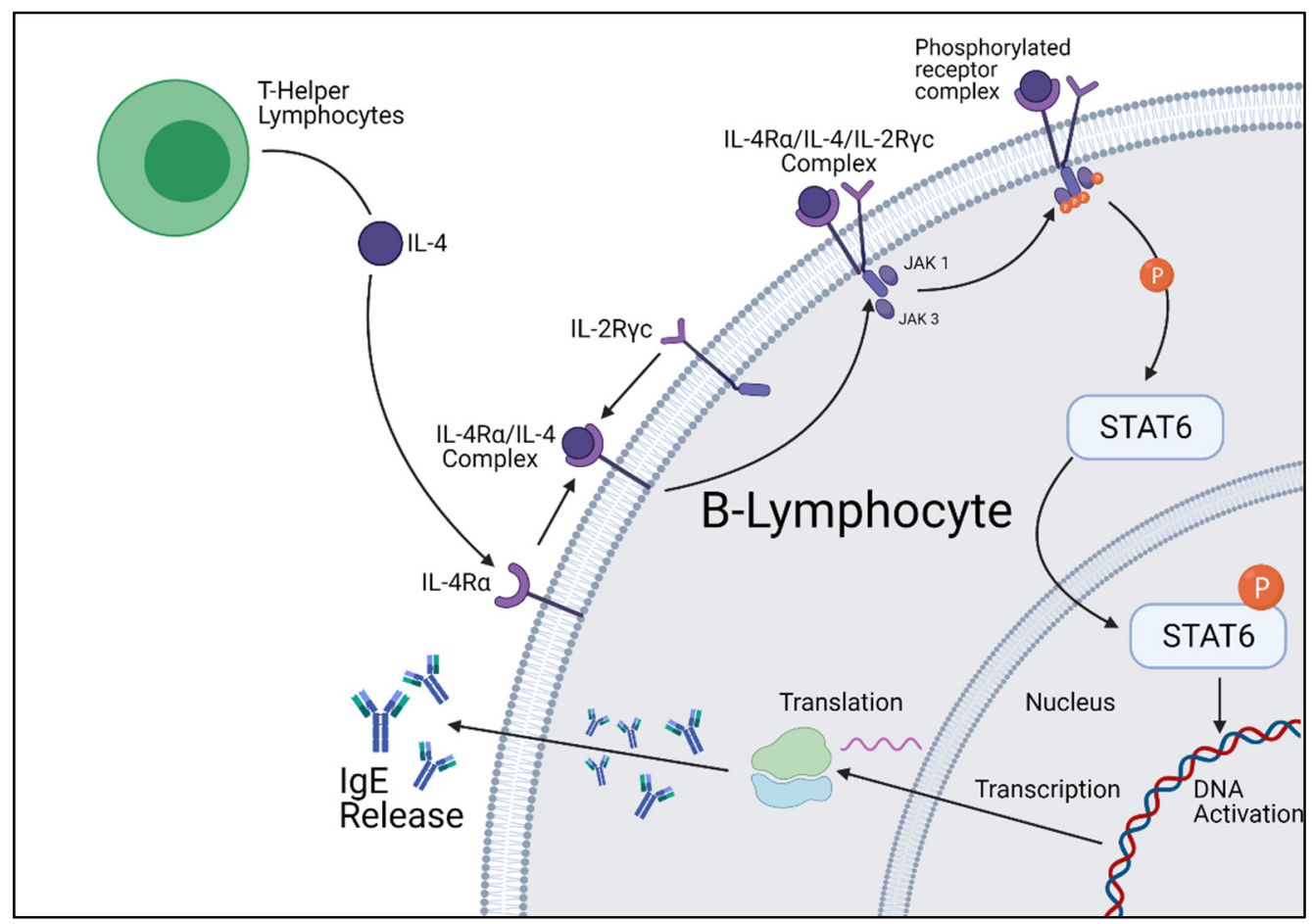

Figure 2. Cellular summary of B-lymphocyte IgE production initiated by IL-4 stimulation. Figure was created by the authors and reproduced with permission from BioRender.com (accessed on 19 November 2021).

\section{Other Interleukin Pathways}

IL-4 and IL-13 are not the sole interleukin cytokines responsible for airway inflammation. Whilst IL-4 and IL-13 cause the release of IgE and proinflammatory molecules from B-lymphocytes, proinflammatory molecules released from eosinophils play a pivotal role in causing airway inflammation and asthmatic symptoms [25]. Eosinophilic inflammation is a hallmark of all forms of asthma, and is a consequence of the uncontrolled production of IL-4, IL-13, and IL-5 [26]. IL-5 is the strongest activator of eosinophilic inflammation, capable of stimulating both eosinophil production and mast cell activation [27]. It is important to note that allergic reactions are a complex series of reactions involving intercellular communication. IL-4 and IL-13 are not the sole pathways responsible for the aforementioned allergy symptoms; however, their inhibitions have proven to be effective treatments.

\section{IL-4 Pathway Inhibition}

Due to their integral role in the production of IgE, the IL-4 and IL-13 cytokine pathways have been investigated as a target for potential therapeutic intervention. There exist 
a number of compounds that inhibit aspects of these cytokine pathways, although the only one that has been developed into a therapeutic that is approved for clinical use is dupilumab, a monoclonal antibody therapy that targets the IL-4 and IL-13 membrane receptors, specifically the alpha subunit of the IL- $4 R \alpha$ receptor. The IL- $4 R \alpha$ receptor is involved in both cytokine pathways, thereby making it the prime target for therapeutic inhibition. Dupilumab is currently approved for clinical use in the treatment of severe atopic dermatitis, though this treatment is invasive, requiring regular subdermal injections. There have been investigations into the use of dupilumab for the treatment of asthma, displaying promising results [28]. In one such study, conducted by Castro et al. in 2018, severe asthmatic patients were treated with either dupilumab or a placebo. Their results displayed that dupilumab had a significant positive effect in the treatment of asthma, reducing hospitalization visits and asthmatic episodes [29]. With no adverse side effects observed, dupilumab has a promising future, with ongoing studies evaluating and confirming its safety [30]. While only preliminary studies, these trials further solidify that IL-4- and IL-13-related inflammation are directly linked to asthma, and can be a target for therapeutic intervention [31].

Another drug that targets the IL-4 pathway is pascolizumab. This therapeutic is a humanized monoclonal antibody that targets the IL-4 cytokine. Initial animal studies were very promising, displaying almost complete T-cell function inhibition. Studies around this drug showed that pascolizumab had a high binding affinity to IL-4 with a slow dissociation rate [32]. This was coupled with low toxicity and few side effects, although these effects did become more exaggerated after chronic use, due to the drug's long half-life. Previous animal trials have been conducted to evaluate short- and long-term treatment safety. The results from these trials were very promising, with the only complication being the development of an anti-idiotypic response resulting in the rapid clearance of pascolizumab [32]. In more recent years, a phase II clinical trial with pascolizumab was conducted with asthmatic patients. While no issues were raised with the safety of the treatment, the trials were discontinued due to the low efficacy [33].

Unlike the other therapeutics discussed, pitrakinra is a molecular therapeutic currently being investigated for IL-4 pathway inhibition. This peptide is a molecular inhibitor of the IL-4R $\alpha$ surface receptor, competing for binding against both IL-4 and IL-13 [34]. Previous trials have shown pitrakinra having a low effect; however, as the trials progressed, pitrakinra began showing a greatly increased efficacy [35]. After further investigation, this variation was explained through genetic sequence variations between the patient groups, specifically a single nucleotide polymorphism within the IL-4R $\alpha$ gene [36]. Results showed that patients carrying this SNP had a higher success rate than those without. Currently, pitrakinra is being further investigated for therapeutic effects within trials. Pitrakinra is a prime example of the role that genetics play in pharmaceuticals, displaying how a single nucleotide polymorphism can greatly affect the efficacy of a therapeutic. Further phenotypic investigations of the IL-4 and IL-13 pathways are required; this could allow for the subgrouping of patients by their genetic variations, opening the way to personalized therapeutic inhibitions.

\section{IL-13 Inhibition}

The IL-13 pathway, as discussed earlier, plays an integral role in type 1 inflammation, thereby making it a candidate for therapeutic inhibition. There are a number of therapeutic compounds, mostly monoclonal antibodies, that are being evaluated for potential clinical use in IL-13 inhibition (Table 1). Lebrikizumab is the first of these monoclonal antibodies that will be discussed in this review. This antibody inhibits the IL-13 pathway through binding to soluble IL-13, thereby preventing binding to the IL-13 cell surface receptors [37]. There have been a number of trials involving lebrikizumab that have shown positive effects in patients suffering from uncontrolled asthma [38]. While previous trials showed positive effects for asthmatic patients displaying type 1 biomarkers (high blood eosinophil count), a more recent phase II trial conducted in 2016 showed inconsistent reductions in 
asthma exacerbations, indicating further trials and studies are required to fully determine its efficacy in asthma treatment [39].

Table 1. Summary of IL-4 and IL-13 inhibitory drugs currently undergoing or that have undergone clinical trials.

\begin{tabular}{|c|c|c|c|}
\hline Name & Inhibitory Target & Description & Reference \\
\hline Dupilumab & IL-4R $\alpha$ & $\begin{array}{l}\text { Monoclonal antibody targeting the IL- } 14 R \alpha \\
\text { receptor, thereby inhibiting both the IL- } 4 \text { and } \\
\text { IL-13 pathways. Currently approved in the US } \\
\text { for treatment of atopic dermatitis. Under } \\
\text { investigation for asthma treatment. }\end{array}$ & [29-31] \\
\hline Pascolizumab & IL-4 cytokine & $\begin{array}{l}\text { Humanized monoclonal antibody targeting the } \\
\text { IL-4 cytokine. Binding to the cytokine inhibits } \\
\text { prevents receptor binding, preventing the } \\
\text { downstream effects of the IL- } 4 \text { pathway. }\end{array}$ & {$[32,33]$} \\
\hline Pitrakinra & IL- $4 \alpha$ & $\begin{array}{l}\text { Synthetic protein targeting the IL- } 4 \mathrm{R} \alpha \text { receptor. } \\
\text { Like dupilumab, pitrakinra inhibits both the } \\
\text { IL- } 4 \text { and IL- } 13 \text { pathways, though clinical trials } \\
\text { have shown little efficacy, leading to an } \\
\text { investigation into the IL- } 4 \text { R } \alpha \text { genes. }\end{array}$ & [34-36] \\
\hline Lebrikizumab & IL-13 cytokine & $\begin{array}{l}\text { Monoclonal antibody that targets IL- } 13 \\
\text { cytokines, thereby blocking the downstream } \\
\text { pathway. Trials are still being conducted, with } \\
\text { inconsistent results reported. }\end{array}$ & [37-39] \\
\hline Anrukisumab & IL-13 cytokine & $\begin{array}{l}\text { Monoclonal antibody that also targets the IL-13 } \\
\text { cytokine, like lebrikizumab, although it is } \\
\text { aimed at the treatment of ulcerative colitis. } \\
\text { Having only undergone phase I trials, more } \\
\text { study is required. }\end{array}$ & {$[40,41]$} \\
\hline Tralokinumab & IL-13 & $\begin{array}{l}\text { Monoclonal antibody that targets the IL- } 13 \\
\text { cytokine. Having recently undergone phase III } \\
\text { trials, tralokinumab has shown promising } \\
\text { results in the treatment of atopic dermatitis. }\end{array}$ & {$[42,43]$} \\
\hline
\end{tabular}

Anrukisumab is yet another monoclonal humanized anti-IL-13 antibody that inhibits the IL-13 pathway through binding to IL-13, preventing the formation of the receptor/ligand complex. Similarly to lebirkizumab, anrukisumab has been tested in clinical trials for the treatment of asthma, as well as for the treatment of ulcerative colitis $[40,41]$. This monoclonal antibody has, to date, only undergone phase I clinical trials aimed at toxicity; therefore, further studies are required to reach a better understanding of the underlying causes.

Tralokinumab is another humanized monoclonal antibody that also targets the interactions between IL-13 and its receptors. Unlike anrukisumab, tralokinumab has undergone phase II and III clinical trials aimed at finding a treatment for atopic dermatitis [42]. While aimed at atopic dermatitis, this is also relevant to allergen-induced asthma due to the integral role that IL-13 plays. Whilst having undergone a greater number of trials, tralokinumab showed similar flaws to other IL-13 inhibitors, such as inconsistent treatment across patient groups and low efficacy [43]. This demonstrated the intricate and numerous intertwining pathways that contribute towards allergic responses; while IL-4 and IL-13 pathways played integral roles, the pathways clearly varied among individuals. Very recently, phase III clinical trials have concluded for tralokinumab, and it has begun undergoing the review process for FDA approval, which was set to conclude in the second quarter of 2021. Similar to previous trials, the results of these later trials showed differing results between individuals, with some displaying a superior response to the treatment compared to others [44]. 


\section{STAT6 Inhibition}

Due to its integral role in both the Il-4 and Il-13 pathways, STAT6 has been previously investigated as a target for therapeutic inhibition. Experimental models have displayed that targeting the STAT6 transcription factor can inhibit airway inflammation, eosinophil infiltration, and fibrosis [45]. Due to this, a number of peptides have been identified that can bind to this transcription factor, thereby inhibiting its function, although these peptides have yet to be tested in vivo [46]. STAT6, while the prominent transcription factor for the production of IgE, has also been shown to play a number of roles throughout the body. For instance, it has been found that inhibition of STAT6 within gastric carcinoma cells reduced their protein expression, inhibiting their proliferation and migration [47]. Some studies have been performed examining the effect of various STAT6-inhibiting peptides, all with promising results showing decreased tumor growth and spread [48,49]; however, there are yet to be any in vivo preclinical or clinical trials, so the safety of these inhibitors is still relatively unknown.

\section{Concluding Remarks}

The overwhelming majority of inhibitory therapeutics currently being investigated for IL-4 pathway inhibition are immunotherapeutics that involve the use of large, monoclonal antibody molecules targeting either the IL-4 or IL-13 cytokines or their corresponding receptors. While targeting the same receptor or cytokine, these antibodies display different efficacy among patient groups, which can be attributed to small genetic variations, such as the $3^{\prime}$ genetic alteration discovered by the researchers studying lebrikizumab [39]. This emphasizes that more research is required into the minute variations between patient groups to determine the effect they have on treatment efficacy.

Despite targeting the same pathway, the aforementioned pharmaceutical trials displayed significantly different results for different patient groups. Further research into the small interpatient variations discussed previously could greatly increase the efficacy of these treatments while simultaneously opening the doors to personalized allergic treatments via cytokine pathway inhibition. Of the discussed inhibitory drugs, the majority are monoclonal antibody treatments, which carry their own sets of limitations. This type of immunotherapy has specific storage and clinical administration requirements, whilst also being expensive to manufacture [50]. They also require repeated administration when being used to treat autoimmune diseases, leading to high costs for patients and healthcare systems. As a proof of concept, these treatments have illustrated that the inhibition of the IL-4 and IL-13 pathways can effectively treat thunderstorm asthma, although costs and administration must improve before they can be considered as treatments.

Biologic treatment is a growing field offering highly specific and effective therapeutics. Whilst highly effective, biologics have a number of issues ranging from difficult production to invasive administration. Currently, there is one biologic treatment that targets the IL-4 pathway that has been approved, this being the aforementioned dupilumab. It is effective and can completely remove symptoms, although it is expensive and requires subepithelial administration through weekly injections [51]. High production costs and specialized invasive administration are the issues facing all biologic treatments [52,53]. Approaches have been made to deliver these therapeutics through alternative routes; however, there are many barriers. Biologics cannot be administered orally, as the digestive tract breaks down larger proteins and prevents their crossing of gastrointestinal epithelial membranes [54]. Similarly, most biologics are too large to cross the airway epithelium, thereby eliminating that route. Extensive research has been conducted to deliver biologics orally that involve altering and adding molecules to the surface of biologics, allowing them to retain their forms through the gastrointestinal tract and cross the epithelial membranes, although with such a wide variety of biologics, more research is required for better administration [55]. Smaller biological molecules are easier to administer, due to their increased stability and easier crossing of the epithelial membranes, which should be the target for future research. 
This review has highlighted the interleukin 4 and 13 signaling pathways with current therapeutic inhibitors. Of the discussed inhibitors, the majority are immunotherapeutic, such as monoclonal antibodies that target either the cytokine or the receptor. These immunotherapies have their own limitations, as well as varying efficacy among patients, highlighting the need for further phenotyping of patient groups. Ideally, a therapeutic that targets the interleukin cytokine pathways should be easily transportable, noninvasive to administer, and show similar efficacy among patient groups. Due to the lack of success these immunotherapies have displayed against these criteria, perhaps research should focus on smaller, more stable molecules such as peptides or larger proteins, rather than complex immunological therapies.

Author Contributions: O.M. prepared the initial draft of the manuscript; C.S. provided direction and revision of the manuscript. All authors have read and agreed to the published version of the manuscript.

Funding: The authors would like to acknowledge the Institute for Mental and Physical Health and Clinical Translation (IMPACT) at Deakin University for funding.

Acknowledgments: The authors wish to acknowledge the manuscript review by Samuel King and Daniel Coomber of the School of Life and Environmental Sciences, Deakin University.

Conflicts of Interest: The authors declare no conflict of interest.

\section{References}

1. Dierick, B.J.H.; van der Molen, T.; Flokstra-de Blok, B.M.J.; Muraro, A.; Postma, M.J.; Kocks, J.W.H.; van Boven, J.F.M. Burden and socioeconomics of asthma, allergic rhinitis, atopic dermatitis and food allergy. Expert Rev. Pharmacoecon. Outcomes Res. 2020, 20, 437-453. [CrossRef]

2. Igea, J.M. The history of the idea of allergy. Allergy 2013, 68, 966-973. [CrossRef] [PubMed]

3. Global Asthma Network. The Global Asthma Report 2018. Available online: http://globalasthmareport.org/ (accessed on 20 February 2021).

4. Baldacci, S.; Maio, S.; Cerrai, S.; Sarno, G.; Baïz, N.; Simoni, M.; Annesi-Maesano, I.; Viegi, G.; HEALS Study. Allergy and asthma: Effects of the exposure to particulate matter and biological allergens. Respir. Med. 2015, 109, 1089-1104. [CrossRef]

5. CDC COVID-19 Response Team. Coronavirus Disease 2019 in Children-United States, 12 February-2 April 2020. MMWR Morb. Mortal. Wkly. Rep. 2020, 69, 422-426. [CrossRef] [PubMed]

6. Abrams, E.M.; Sinha, I.; Fernandes, R.M.; Hawcutt, D.B. Pediatric asthma and COVID-19: The known, the unknown, and the controversial. Pediatr. Pulmonol. 2020, 55, 3573-3578. [CrossRef] [PubMed]

7. Liu, S.; Zhi, Y.; Ying, S. COVID-19 and Asthma: Reflection During the Pandemic. Clin. Rev. Allergy Immunol. 2020, 59, 78-88. [CrossRef]

8. Mims, J.W. Asthma: Definitions and pathophysiology. Int. Forum Allergy Rhinol. 2015, 5 (Suppl. 1), S2-S6. [CrossRef]

9. Bagnasco, D.; Ferrando, M.; Varricchi, G.; Passalacqua, G.; Canonica, G.W. A Critical Evaluation of Anti-IL-13 and Anti-IL-4 Strategies in Severe Asthma. Int. Arch. Allergy Immunol. 2016, 170, 122-131. [CrossRef] [PubMed]

10. Sullivan, P.W.; Campbell, J.D.; Ghushchyan, V.H.; Globe, G. Outcomes before and after treatment escalation to Global Initiative for Asthma steps 4 and 5 in severe asthma. Ann. Allergy Asthma Immunol. 2015, 114, 462-469. [CrossRef]

11. Bateman, E.D.; Boushey, H.A.; Bousquet, J.; Busse, W.W.; Clark, T.J.; Pauwels, R.A.; Pedersen, S.E.; GOAL Investigators Group. Can guideline-defined asthma control be achieved? The Gaining Optimal Asthma ControL study. Am. J. Respir. Crit. Care Med. 2004, 170, 836-844. [CrossRef]

12. Gieseck, R.L.; Wilson, M.S.; Wynn, T.A. Type 2 immunity in tissue repair and fibrosis. Nat. Rev. Immunol. 2018, 18, 62-76. [CrossRef]

13. Bao, K.; Reinhardt, R.L. The differential expression of IL-4 and IL-13 and its impact on type-2 immunity. Cytokine 2015, 75, 25-37. [CrossRef]

14. Busse, W.W. Biological treatments for severe asthma: A major advance in asthma care. Allergol. Int. 2019, 68, 158-166. [CrossRef] [PubMed]

15. Zhu, J. T helper 2 (Th2) cell differentiation, type 2 innate lymphoid cell (ILC2) development and regulation of interleukin-4 (IL-4) and IL-13 production. Cytokine 2015, 75, 14-24. [CrossRef] [PubMed]

16. Antczak, A.; Domanska-Senderowska, D.; Gorski, P.; Pastuszak-Lewandoska, D.; Nielepkowicz-Gozdzinska, A.; Szewczyk, K.; Kurmanowska, Z.; Kiszałkiewicz, J.; Brzeziańska-Lasota, E. Analysis of changes in expression of IL-4/IL-13/STAT6 pathway and correlation with the selected clinical parameters in patients with atopic asthma. Int. J. Immunopathol. Pharmacol. 2016, 29, 195-204. [CrossRef]

17. Kelly-Welch, A.; Hanson, E.M.; Keegan, A.D. Interleukin-4 (IL-4) pathway. Sci. Signal. 2005, 2005, cm9. [CrossRef] 
18. Sheikh, F.; Dickensheets, H.; Pedras-Vasconcelos, J.; Ramalingam, T.; Helming, L.; Gordon, S.; Donnelly, R.P. The Interleukin-13 Receptor- $\alpha 1$ Chain Is Essential for Induction of the Alternative Macrophage Activation Pathway by IL-13 but Not IL-4. J. Innate Immun. 2015, 7, 494-505. [CrossRef] [PubMed]

19. Kelly-Welch, A.; Hanson, E.M.; Keegan, A.D. Interleukin-13 (IL-13) pathway. Sci. Signal. 2005, 2005, cm8. [CrossRef] [PubMed]

20. Wu, W.J.; Wang, S.H.; Wu, C.C.; Su, Y.A.; Chiang, C.Y.; Lai, C.H.; Wang, T.H.; Cheng, T.-L.; Kuo, J.-Y.; Hsu, T.-C.; et al. IL-4 and IL-13 Promote Proliferation of Mammary Epithelial Cells through STAT6 and IRS-1. Int. J. Mol. Sci. 2021, 22, 12008. [CrossRef]

21. Liu, C.; Richard, K.; Wiggins, M.; Zhu, X.; Conrad, D.H.; Song, W. CD23 can negatively regulate B-cell receptor signaling. Sci. Rep. 2016, 6, 25629. [CrossRef]

22. Kneitz, C.; Goller, M.; Seggewiss, R.; Yaman, A.; Serfling, E.; Tony, H.P. STAT6 and the regulation of CD23 expression in B-chronic lymphocytic leukemia. Leuk. Res. 2000, 24, 331-337. [CrossRef]

23. Walford, H.H.; Doherty, T.A. STAT6 and lung inflammation. JAK-STAT 2013, 2, e25301. [CrossRef]

24. Singh, D.; Ravi, A.; Southworth, T. CRTH2 antagonists in asthma: Current perspectives. Clin. Pharmacol. 2017, 9, 165-173. [CrossRef] [PubMed]

25. Lauder, A.J.; McKenzie, A.N.J.; Sanderson, C.J. Interleukin-5. In Encyclopedia of Hormones; Henry, H.L., Norman, A.W., Eds.; Academic Press: New York, NY, USA, 2003; pp. 422-429.

26. Pelaia, C.; Paoletti, G.; Puggioni, F.; Racca, F.; Pelaia, G.; Canonica, G.W.; Heffler, E. Interleukin-5 in the Pathophysiology of Severe Asthma. Front. Physiol. 2019, 10, 1514. [CrossRef]

27. Greenfeder, S.; Umland, S.P.; Cuss, F.M.; Chapman, R.W.; Egan, R.W. Th2 cytokines and asthma. The role of interleukin-5 in allergic eosinophilic disease. Respir. Res. 2001, 2, 71-79. [CrossRef]

28. Wenzel, S.; Castro, M.; Corren, J.; Maspero, J.; Wang, L.; Zhang, B.; Pirozzi, G.; Sutherland, E.R.; Evans, R.R.; Joish, V.N.; et al. Dupilumab efficacy and safety in adults with uncontrolled persistent asthma despite use of medium-to-high-dose inhaled corticosteroids plus a long-acting $\beta 2$ agonist: A randomised double-blind placebo-controlled pivotal phase $2 \mathrm{~b}$ dose-ranging trial. Lancet 2016, 388, 31-44. [CrossRef]

29. Castro, M.; Corren, J.; Pavord, I.D.; Maspero, J.; Wenzel, S.; Rabe, K.F.; Busse, W.W.; Ford, L.; Sher, L.; FitzGerald, J.M.; et al. Dupilumab Efficacy and Safety in Moderate-to-Severe Uncontrolled Asthma. N. Engl. J. Med. 2018, 378, 2486-2496. [CrossRef]

30. McGregor, M.C.; Krings, J.G.; Nair, P.; Castro, M. Role of Biologics in Asthma. Am. J. Respir. Crit. Care Med. 2019, 199, 433-445. [CrossRef] [PubMed]

31. Santini, G.; Mores, N.; Malerba, M.; Mondino, C.; Anzivino, R.; Macis, G.; Montuschi, P. Dupilumab for the treatment of asthma. Expert Opin. Investig. Drugs 2017, 26, 357-366. [CrossRef] [PubMed]

32. Hart, T.K.; Blackburn, M.N.; Brigham-Burke, M.; Dede, K.; Al-Mahdi, N.; Zia-Amirhosseini, P.; Cook, R.M. Preclinical efficacy and safety of pascolizumab (SB 240683): A humanized anti-interleukin-4 antibody with therapeutic potential in asthma. Clin. Exp. Immunol. 2002, 130, 93-100. [CrossRef] [PubMed]

33. Long, A.A. Monoclonal antibodies and other biologic agents in the treatment of asthma. MAbs 2009, 1, 237-246. [CrossRef] [PubMed]

34. Antoniu, S.A. Pitrakinra, a dual IL-4/IL-13 antagonist for the potential treatment of asthma and eczema. Curr. Opin. Investig. Drugs 2010, 11, 1286-1294.

35. Slager, R.E.; Otulana, B.A.; Hawkins, G.A.; Yen, Y.P.; Peters, S.P.; Wenzel, S.E.; Meyers, D.A.; Bleecker, R. IL-4 receptor polymorphisms predict reduction in asthma exacerbations during response to an anti-IL-4 receptor alpha antagonist. J. Allergy Clin. Immunol. 2012, 130, 516-522.e4. [CrossRef] [PubMed]

36. Pennington, E.J.; Wechsler, M.E.; Ortega, V.E. Chapter 9-Pharmacogenomics and Applications to Asthma Management. In Personalizing Asthma Management for the Clinician; Szefler, S.J., Holguin, F., Wechsler, M.E., Eds.; Elsevier: Amsterdam, The Netherlands, 2018; pp. 97-112.

37. Loh, T.Y.; Hsiao, J.L.; Shi, V.Y. Therapeutic Potential of Lebrikizumab in the Treatment of Atopic Dermatitis. J. Asthma Allergy 2020, 13, 109-114. [CrossRef] [PubMed]

38. Corren, J.; Lemanske, R.F.; Hanania, N.A.; Korenblat, P.E.; Parsey, M.V.; Arron, J.R.; Harris, J.M.; Scheerens, H.; Wu, L.C.; Su, Z.; et al. Lebrikizumab treatment in adults with asthma. N. Engl. J. Med. 2011, 365, 1088-1098. [CrossRef] [PubMed]

39. Hanania, N.A.; Korenblat, P.; Chapman, K.R.; Bateman, E.D.; Kopecky, P.; Paggiaro, P.; Yokoyama, A.; Olsson, J.; Gray, S.; Holweg, C.T.; et al. Efficacy and safety of lebrikizumab in patients with uncontrolled asthma (LAVOLTA I and LAVOLTA II): Replicate, phase 3, randomised, double-blind, placebo-controlled trials. Lancet Respir. Med. 2016, 4, 781-796. [CrossRef]

40. Hua, F.; Ribbing, J.; Reinisch, W.; Cataldi, F.; Martin, S. A pharmacokinetic comparison of anrukinzumab, an anti- IL-13 monoclonal antibody, among healthy volunteers, asthma and ulcerative colitis patients. Br. J. Clin. Pharmacol. 2015, 80, 101-109. [CrossRef]

41. Reinisch, W.; Panes, J.; Khurana, S.; Toth, G.; Hua, F.; Comer, G.M.; Hinz, M.; Page, K.; O’Toole, M.; McDonnell Moorehead, T.; et al. Anrukinzumab, an anti-interleukin 13 monoclonal antibody, in active UC: Efficacy and safety from a phase IIa randomised multicentre study. Gut 2015, 64, 894-900. [CrossRef] [PubMed]

42. Apter, A.J. The tralokinumab story: Nothing is ever simple. J. Allergy Clin. Immunol. 2019, 143, 1336-1338. [CrossRef] [PubMed]

43. Panettieri, R.A., Jr.; Wang, M.; Braddock, M.; Bowen, K.; Colice, G. Tralokinumab for the treatment of severe, uncontrolled asthma: The ATMOSPHERE clinical development program. Immunotherapy 2018, 10, 473-490. [CrossRef] [PubMed] 
44. ClinicalTrials.gov. Tralokinumab in Combination with Topical Corticosteroids for Moderate to Severe Atopic DermatitisECZTRA 3. 2021. Available online: https://clinicaltrials.gov/ct2/show/NCT03363854 (accessed on 16 November 2021).

45. Oh, C.K.; Geba, G.P.; Molfino, N. Investigational therapeutics targeting the IL-4/IL-13/STAT-6 pathway for the treatment of asthma. Eur. Respir. Rev. 2010, 19, 46-54. [CrossRef] [PubMed]

46. Stolzenberger, S.; Haake, M.; Duschl, A. Specific inhibition of interleukin-4-dependent Stat6 activation by an intracellularly delivered peptide. Eur. J. Biochem. 2001, 268, 4809-4814. [CrossRef] [PubMed]

47. Lu, G.; Shi, W.; Zheng, H. Inhibition of STAT6/Anoctamin-1 Activation Suppresses Proliferation and Invasion of Gastric Cancer Cells. Cancer Biother. Radiopharm. 2018, 33, 3-7. [CrossRef] [PubMed]

48. Delgado-Ramirez, Y.; Colly, V.; Villanueva Gonzalez, G.; Leon-Cabrera, S. Signal transducer and activator of transcription 6 as a target in colon cancer therapy. Oncol. Lett. 2020, 20, 455-464. [CrossRef] [PubMed]

49. Mendoza-Rodríguez, M.G.; Sánchez-Barrera, C.Á.; Callejas, B.E.; García-Castillo, V.; Beristain-Terrazas, D.L.; Delgado-Buenrostro, N.L.; Chirino, Y.I.; León-Cabrera, S.A.; Rodriguez-Sosa, M.; Gutierrez-cirlos, E.B.; et al. Use of STAT6 Phosphorylation Inhibitor and Trimethylglycine as New Adjuvant Therapies for 5-Fluorouracil in Colitis-Associated Tumorigenesis. Int. J. Mol. Sci. 2020, 21, 2130. [CrossRef] [PubMed]

50. Sparrow, E.; Friede, M.; Sheikh, M.; Torvaldsen, S. Therapeutic antibodies for infectious diseases. Bull. World Health Organ. 2017, 95, 235-237. [CrossRef]

51. Zimmermann, M.; Rind, D.; Chapman, R.; Kumar, V.; Kahn, S.; Carlson, J. Economic Evaluation of Dupilumab for Moderate-toSevere Atopic Dermatitis: A Cost-Utility Analysis. J. Drugs Dermatol. 2018, 17, 750-756. [PubMed]

52. Anselmo, A.C.; Gokarn, Y.; Mitragotri, S. Non-invasive delivery strategies for biologics. Nat. Rev. Drug Discov. 2019, 18, 19-40. [CrossRef]

53. Saeed, A.F.; Wang, R.; Ling, S.; Wang, S. Antibody Engineering for Pursuing a Healthier Future. Front. Microbiol. $2017,8,495$. [CrossRef]

54. Matucci, A.; Vultaggio, A.; Danesi, R. The use of intravenous versus subcutaneous monoclonal antibodies in the treatment of severe asthma: A review. Respir. Res. 2018, 19, 154. [CrossRef]

55. Drucker, D.J. Advances in oral peptide therapeutics. Nat. Rev. Drug Discov. 2020, 19, 277-289. [CrossRef] [PubMed] 